\title{
Produção de mudas de framboeseira negra por diferentes métodos de propagação vegetativa
}

\author{
Seedling production of black raspberry by different methods of vegetative propagation \\ Kelly Nascimento Silva ${ }^{\mathrm{I}}$ Rafael Pio $^{\mathrm{I} *}$ Maraisa Hellen Tadeu ${ }^{\mathrm{I}}$ Cynthia Natally de Assis ${ }^{\mathrm{I}}$ \\ Paula Nogueira Curi ${ }^{I}$ Pedro Henrique Abreu Moura ${ }^{\mathrm{I}}$ Leonardo Silva Patto ${ }^{\mathrm{I}}$
}

\section{RESUMO}

Visando estudar técnicas de propagação vegetativa da framboeseira negra (Rubus niveus) por estaquia e mergulhia, o objetivo do presente trabalho foi verificar o potencial rizogênico de estacas caulinares, radiculares, mergulhia de ponta e alporquia dessa espécie. No primeiro experimento, estacas radiculares e caulinares de $10 \mathrm{~cm}$ foram tratadas com diferentes concentrações de ácido indolbutírico (AIB): 1000, 2000, 3000 e $4000 \mathrm{mg} \mathrm{L}^{-1}$ por 10 segundos, além do controle composto somente por água. No segundo experimento, as estacas foram armazenadas a frio por 10, 20 e 30 dias, além do controle sem armazenamento. Em ambos os experimentos, as estacas caulinares foram enterradas 2/3 de seu comprimento na posição vertical e as estacas radiculares foram totalmente imersas na posição horizontal, utilizando a vermiculita de grânulos finos como substrato, em telado com sombreamento de $50 \%$ e, após 60 dias, foram avaliadas. No terceiro experimento, a mergulhia de ponta e alporquia foram realizadas na porção mediana dos ramos, aplicando-se no local diferentes concentrações de AIB $\left(0,1000,2000\right.$ e $\left.3000 \mathrm{mg} \mathrm{L}^{-1}\right)$ e, em seguida, foram envolvidos pelo substrato casca de pinus umedecido. Passados 45 dias, foram removidos para a mensuração. Concluiu-se que as estacas caulinares apresentam resultados superiores em comparação com as estacas radiculares, não necessitando armazenar a frio e não tratar com AIB; a mergulhia de ponta promoveu maior emissão de raízes em comparação com a alporquia.

Palavras-chave: Rubus niveus, produção de mudas, ácido indolbutirico, armazenamento a frio.

\section{ABSTRACT}

Aiming to develop a propagation protocol through black raspberry (Rubus niveus) cutting and layering, the objective of the present research was to quantify the rizogenic potential of stems and roots cuttings, point and air layering of this specie. In the first experiment, the stems and roots cuttings of $10 \mathrm{~cm}$ of length were treated with different concentrations of indolbutyric acid (IBA): 1000, 2000, 3000 and 4000mg L $\mathrm{L}^{-1}$ for 10 seconds. In the second experiment, the stems and roots cuttings of black raspberry were cold storage by 10, 20 and 30 days, and control without storage. In both experiments, the stems cuttings were buried $2 / 3$ length in the vertical position and the roots cuttings were totally immerged in the horizontal position, using the vermiculita as substrate, in greenhouse with $50 \%$ of light. After 60 days, they were evaluated. In the third experiment, the point and air layering were accomplished in the medium portion of the branches, being applied in the place different concentrations of IBA $\left(0,1000,2000\right.$ and $\left.3000 \mathrm{mg} \mathrm{L}^{-1}\right)$ and soon after, they were involved by the following humidified pinus substrate. After 45 days they were removed for the evaluation. It can be concluded that the stems cuttings presents better results in comparison by roots cuttings, owing cold storage and without IBA; the point layering promoted larger emission of roots in comparison to air layering.

Key words: Rubus niveus, seedlings production, indolbutyric acid, cold storage.

\section{INTRODUÇÃO}

A framboseira negra (Rubus niveus Thunberg), também conhecida como raspberry-demysore e raspberry-do-morro, adapta-se bem nas regiões de inverno ameno e com temperaturas moderadas. É um arbusto espinhoso que tem talos esbranquiçados pequenos, com flores arranjadas em uma panícula terminal, que produzem frutos agregados de tamanho diminuto (2 a 5 gramas), com coloração púrpura a negra (PARMAR \& KAUSHAL, 1982). Essa framboeseira destaca-se pelas características nutricionais de seus frutos, que contém mais de 230mg $100 \mathrm{~g}^{-1}$ de antocianina total, mais que o dobro da quantidade apresentada pela amora-preta (Rubus spp.) e a framboesa vermelha (Rubus idaeus) (MOYER et al., 2002; JIN et al., 2008).

No Brasil, a framboeseira negra encontra-se dispersa por toda a Mata Atlântica e Serra da Mantiqueira. Alguns pomares caseiros foram instalados na região de Campos do Jordão-SP e seus

IUniversidade Federal de Lavras (UFLA), 37200-000, Lavras, MG, Brasil. E-mail: rafaelpio@dag.ufla.br. *Autor para correspondência. 
frutos são comercializados no comércio local turístico, principalmente para a confecção de geléias caseiras e sucos (RASEIRA et al., 2004). A literatura sobre essa framboeseira é escassa. É apenas multiplicada por sementes (LORENZI et al., 2006) e usualmente vem sendo adotada pelos produtores da Serra da Mantiqueira, principalmente pelo fato de essa framboeseira emitir poucos rebentos do sistema radicular, diferentemente das framboeseiras da espécie Rubus idaeus, e por não ter sido realizados estudos sobre métodos de propagação vegetativa para essa espécie. No caso especial da amora-preta, a propagação pode ser realizada através de estacas de raízes ou estacas caulinares coletadas no período hibernal (ANTUNES et al., 2000). Como a framboeseira negra possui espinhos igualmente à amora-preta, a utilização de estacas radiculares poderia facilitar a operação e o manuseio das estacas.

Algumas técnicas têm sido utilizadas visando a potencializar a emissão de raízes na propagação por estacas. Uma delas é a utilização do ácido indolbutírico (AIB) que, segundo HAN et al. (2009), é uma auxina foto-estável que vem sendo usualmente empregada no enraizamento de espécies que possuem baixa capacidade rizogênica. Outra técnica é o armazenamento das estacas em baixas temperaturas, que, segundo PIO et al. (2007a), auxiliam na superação da endodormência das gemas e propiciam aumento da emissão de raízes nas estacas.

Já a mergulhia, outra técnica de propagação vegetativa, concilia o enraizamento de uma porção do ramo ainda conectado à planta-matriz, melhorando as condições para que a rizogênese aconteça. A propagação pelo método de mergulhia apresenta vantagens em relação à estaquia, dentre as quais estão $o$ alto percentual de enraizamento e a independência de infraestrutura (casa de vegetação com sistema de nebulização), sendo essa uma alternativa potencial no enraizamento (PIO et al., 2007b; DANELUZ et al., 2009).

Visando a estudar a propagação vegetativa da framboeseira negra, o referido trabalho teve como objetivo verificar o potencial de enraizamento de estacas caulinares e radiculares, bem como a mergulhia aérea e de ponta.

\section{MATERIAL E MÉTODOS}

Foram realizados três experimentos, sendo os dois primeiros com estacas caulinares e radiculares e o terceiro com a mergulhia aérea (alporquia) e mergulhia de ponta, entre os meses de abril a julho de 2010. Os propágulos foram coletados em plantas de framboeseira negra de um ano de idade, propagadas por rebentos e mantidas a campo no Setor de Fruticultura da Universidade Federal de Lavras (UFLA), Lavras-MG

As estacas caulinares foram coletadas em ramos semilenhosos e foram padronizadas com $10 \mathrm{~cm}$ de comprimento e diâmetro ao redor de $7 \mathrm{~mm}$, sendo efetuado um corte reto no ápice da estaca e outro em bisel na base, removendo-se as folhas contidas nas estacas; já as estacas radiculares foram padronizadas com $10 \mathrm{~cm}$ de comprimento e diâmetro ao redor de $10 \mathrm{~mm}$, com cortes retos em ambas as extremidades.

No primeiro experimento, a base das estacas foi tratada com diferentes concentrações de AIB: 1000, 2000, 3000 e 4000 $\mathrm{mg} \mathrm{L}^{-1}$ por 10 segundos, além do controle composto somente por água. $O$ delineamento utilizado foi o inteiramente casualizado, utilizado um fatorial 2x5 (tipo de estaca e concentrações de AIB), com quatro repetições e dez estacas por unidade experimental. Já no segundo experimento, as estacas foram separadas em feixes de dez estacas e posteriormente foram embrulhadas em jornal umedecido e colocadas dentro de sacos plásticos vedados, sendo armazenadas em geladeira (temperatura próxima a $4^{\circ} \mathrm{C}$ ) por diferentes períodos: 10, 20 e 30 dias, além do controle, que foi constituído por uma parte de estacas (feixes de estacas caulinares e radiculares) que não passaram pelo processo de armazenamento. O delineamento utilizado foi o inteiramente casualizado, utilizando um fatorial 2x4 (tipo de estaca e períodos de armazenamento), com quatro repetições e dez estacas por unidade experimental.

Em ambos os experimentos, as estacas caulinares foram enterradas $2 / 3$ de seu comprimento na posição vertical e as estacas radiculares foram totalmente imersas na posição horizontal, a $3 \mathrm{~cm}$ de profundidade, em leito de enraizamento preenchido com vermiculita de grânulos finos, localizado dentro de telado com sombreamento de $50 \%$. As estacas foram diariamente umedecidas e, ao final de 60 dias após o estaqueamento, foram mensuradas a porcentagem de estacas vivas, enraizadas, brotadas, o número médios de brotos e raízes e o comprimento médio das brotações. Já no terceiro experimento, foram realizadas mergulhias por dois métodos em ramos semilenhosos da framboeseira negra: mergulhia de ponta e alporquia, segundo as recomendações de DANELUZ et al. (2009). Na mergulhia de ponta, foram realizados cortes em bisel na extremidade de ramos semilenhosos e na alporquia foram removidas as brotações laterais na porção mediana dos ramos. Posteriormente à realização dos cortes em bisel e confecção dos alporques, foram aplicadas diferentes concentrações de AIB: 1000, 2000 e 3000 $\mathrm{mg} \mathrm{L}^{-1}$, além do controle composto somente por água, com auxílio de um pincel de cerdas finas.

Na mergulhia de ponta, enterrou-se $15 \mathrm{~cm}$ da extremidade em caixas plásticas preenchidas com substrato a base de casca de pinus de grânulos finos umedecida, que foram diariamente umedecidos. Já na alporquia, envolveu-se uma parte de aproximadamente $10 \mathrm{~cm}$ de comprimento com o mesmo substrato a base de casca de pinus umedecida, envolvendo-se em seguida o local com plástico transparente e amarrandose as extremidades, para evitar a perda de umidade. O delineamento utilizado foi o inteiramente casualizado, em um fatorial 2x4 (tipo de mergulhia e concentrações de AIB), com quatro repetições e dez ramos de plantas diferentes por unidade experimental. Ao final de 45 dias, 
foram mensuradas a porcentagem de enraizamento e o número médio de raízes.

Para a análise estatística, foi aplicado o teste de comparação de médias Tukey e regressão, ao nível de $5 \%$ de probabilidade, sendo utilizado o programa Sistema para Análise de Variância - SISVAR.

\section{RESULTADOS E DISCUSSÃO}

No primeiro experimento, as estacas radiculares e caulinares tratadas com 2000, 3000 e 4000mg $\mathrm{L}^{-1}$ de AIB não sobreviveram. Devido a esse fato, apenas foi realizada a análise estatística com a concentração de $1000 \mathrm{mg} \mathrm{L}^{-1}$ de AIB e o controle. A análise revelou que não houve interação entre os fatores, apenas diferença estatística entre os tratamentos isolados (tipo de estaca e concentração de AIB).

As estacas caulinares e radiculares apresentaram similaridade quanto à porcentagem de estacas vivas, enraizadas, número de brotos e comprimento médio das brotações (Tabela 1). Porém, as estacas caulinares apresentaram resultados superiores quanto à porcentagem de estacas brotadas (60\%) e número de raízes emitidas (14,3), com incremento de $45,7 \%$ e 11,7 raízes, respectivamente, em relação às estacas radiculares.

No caso da amora-preta (Rubus spp.), segundo ANTUNES (2002), pode-se utilizar tanto estacas radiculares como caulinares. $\mathrm{O}$ autor ressalta que as estacas coletadas em ramos em vegetação possuem maior capacidade em emitir raízes e não menciona o potencial rizogênico das estacas radiculares. Pelo exposto, percebe-se que estacas caulinares da framboeseira negra possuem maior potencialidade para serem utilizadas na propagação, em relação às estacas radiculares.

Quanto ao tratamento das estacas com a solução de $1000 \mathrm{mg} \mathrm{L}^{-1}$ de AIB, houve decréscimos dos resultados obtidos em relação ao controle para todas as mensurações realizadas, a exceção da porcentagem de estacas vivas (Tabela 1). Percebe-se pelo exposto que os índices foram superiores em relação ao tratamento com AIB, principalmente quanto à porcentagem de estacas enraizadas (62,5\%) e número de raízes (11). Esses resultados concordam com VILLA et al. (2003) que, trabalhando com o enraizamento de estacas caulinares da amoreira-preta (Rubus spp.) cv. Brazos, pertencente ao mesmo gênero da framboeseira negra (Rubus), constataram que o tratamento com AIB desfavoreceu o enraizamento das estacas. Acredita-se que os níveis endógenos das auxinas nas estacas estavam em um patamar que auxiliasse na emissão das raízes. A suplementação exógena possivelmente ocasionou efeito fitotóxico, desfavorecendo assim o enraizamento.

Já para o segundo experimento, houve interação entre os fatores para todas as variáveis mensuradas, porém, para a porcentagem de estacas vivas e o comprimento médio das brotações, não houve interação e nem diferença significativa entre o tipo de estaca e os períodos de armazenamento.

Para a porcentagem de enraizamento, estacas caulinares demonstraram maior enraizamento quando foram armazenadas a frio por dois dias, segundo a equação da regressão. No entanto, o aumento da porcentagem de enraizamento foi apenas de $0,4 \%$ em relação ao controle, em que foram registrados $74 \%$ de estacas enraizadas (Figura 1A). Para as estacas radiculares, o armazenamento por 14 dias favoreceu 0 aumento de $35 \%$ de enraizamento das estacas, em relação ao controle, que propiciou apenas $44 \%$ de estacas enraizadas. Por esses resultados, percebe-se que o índice de enraizamento das estacas caulinares sem armazenamento (74\%) e das estacas radiculares armazenadas a frio por 14 dias $(79,81 \%)$ foram próximos. Estacas caulinares registraram 25,59 raízes emitidas quando foram armazenadas por 11 dias (9,41 a mais em relação ao controle) e estacas radiculares 10,53 raízes emitidas quando foram armazenadas por 23 dias (8 raízes a mais que o controle) (Figura 1B). Apesar desses resultados, observa-se que estacas caulinares não armazenadas apresentaram maior emissão de raízes em comparação com as estacas radiculares, mesmo armazenando estas a frio.

Estacas caulinares sem armazenamento apresentaram $83,5 \%$ de brotação e as estacas

Tabela 1 - Porcentagem de estacas vivas (EV, \%), enraizadas (EE, \%), brotadas (EB, \%), nº médio de brotos (NMB) e raízes (NMR) e comprimento médio das brotações $(\mathrm{CMB}, \mathrm{cm})$ de estacas caulinares e radiculares de framboeseira negra, tratadas ou não com $1000 \mathrm{mg} \mathrm{L}^{-1}$. Lavras, UFLA, 2010.

\begin{tabular}{|c|c|c|c|c|c|c|}
\hline \multirow{2}{*}{ Tipo de estaca } & \multirow[b]{2}{*}{ EV (\%) } & \multirow[b]{2}{*}{ ER (\%) } & \multirow[b]{2}{*}{ EB (\%) } & \multirow[b]{2}{*}{ NB } & \multirow[b]{2}{*}{ NR } & \multirow[b]{2}{*}{$\mathrm{CMB}(\mathrm{cm})$} \\
\hline & & & & & & \\
\hline Caulinar & 57,5 a & $42,5 \mathrm{a}$ & $60,0 \mathrm{a}$ & $1,4 \mathrm{a}$ & $14,3 \mathrm{a}$ & $1,3 \mathrm{a}$ \\
\hline Radicular & $54,3 \mathrm{a}$ & $31,4 \mathrm{a}$ & $14,3 \mathrm{~b}$ & $1,0 \mathrm{a}$ & $2,6 \quad b$ & 0,9 a \\
\hline \multicolumn{7}{|l|}{ AIB } \\
\hline 0 & 60,0 a & 62,5 a & $45,0 \mathrm{a}$ & $1,6 \mathrm{a}$ & $11,0 \mathrm{a}$ & $1,7 \mathrm{a}$ \\
\hline $1000\left(\mathrm{mg} \mathrm{L}^{-1}\right)$ & 51,4 a & $8,6 \mathrm{~b}$ & $31,4 \mathrm{~b}$ & $0,8 \mathrm{~b}$ & $6,3 \mathrm{~b}$ & $0,3 \mathrm{~b}$ \\
\hline CV(\%) & 33,0 & 14,2 & 25,5 & 16,5 & 23,4 & 20,1 \\
\hline
\end{tabular}

* Médias não seguidas pela mesma letra diferem significativamente entre si, pelo teste Tukey, em nível de 5\% de probabilidade. 

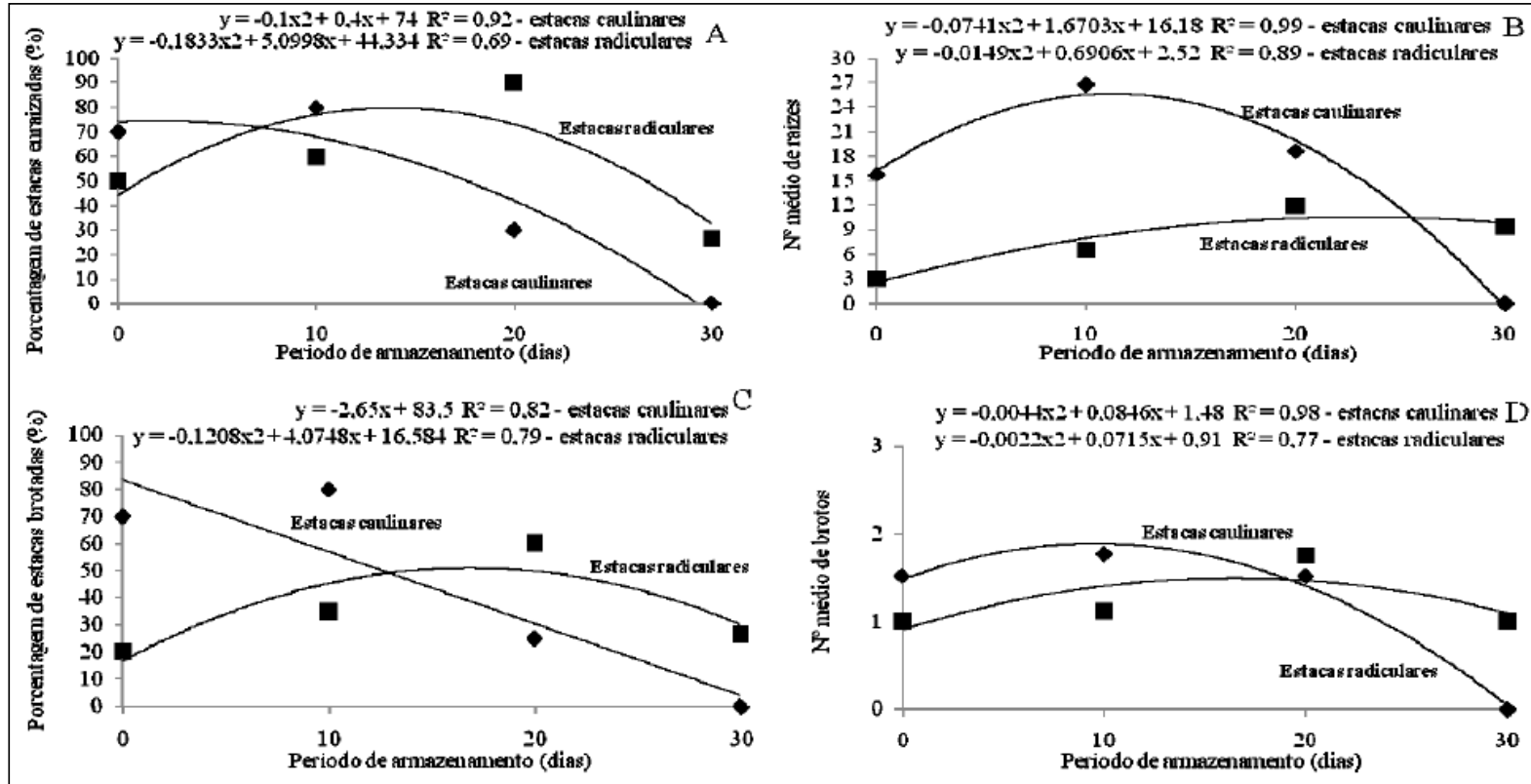

Figura 1 - Porcentagem de estacas enraizadas (A), número médio de raízes (B), porcentagem de estacas brotadas (C) e número médio de brotos (D) em estacas caulinares e radiculares da framboeseira negra armazenadas a frio-úmido por diferentes períodos Lavras, UFLA, 2010.

radiculares, quando foram armazenadas por 17 dias, 50,95\% de brotação (Figura 1C). A emissão de brotos aumentou com o armazenamento das estacas a frio, obtendo-se maior emissão de brotos em estacas caulinares armazenadas por 10 dias (2,28 brotos) e estacas radiculares armazenadas por 16 dias $(1,49$ brotos) (Figura 1D). Esses resultados concordam com RASEIRA et al. (2004), que mencionaram que a utilização de estacas caulinares é uma excelente opção como fonte de material propagativo de $\boldsymbol{R u b u s ~ s p p . ~}$

No terceiro experimento, houve interação entre os fatores para as duas mensurações realizadas. Os resultados evidenciam que houve influência da aplicação do AIB na melhoria do enraizamento e emissão das raízes quando se realizou a alporquia. Segundo o desdobramento da equação da regressão, a concentração de $1634 \mathrm{mg} \mathrm{L}^{-1}$ promoveu $45 \%$ de alporques enraizados (incremento de 42,75\% em relação ao controle) (Figura 2A) e a concentração de $1536 \mathrm{mg} \mathrm{L}^{-1}$ promoveu a emissão de 8,1 raízes (incremento de aproximadamente 7 raízes em relação ao controle) (Figura 2B). No entanto, os melhores resultados foram obtidos com a mergulhia de ponta, em que foram detectados $77,9 \%$ de enraizamento (Figura 2A) e 72,92 raízes (Figura 2B), sem a utilização do AIB.

Fazendo uma análise dos resultados de todos os experimentos, fica nítido que o processo de multiplicação vegetativa da framboeseira negra por mergulhia de ponta propiciou melhores resultados de enraizamento e emissão de raízes, em comparação com as estacas caulinares e principalmente em relação às radiculares. Pela figura 3, pode-se ter maior noção do
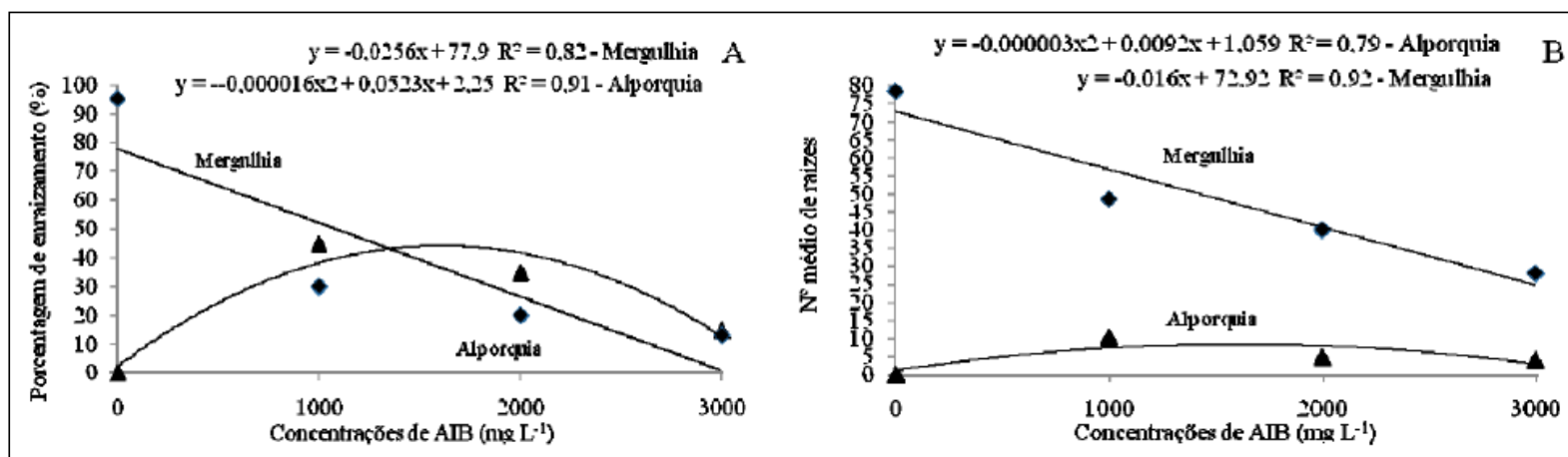

Figura 2 - Porcentagem de estacas enraizadas (A) e número médio de raízes (B) da framboeseira negra submetidas ao enraizamento por mergulhia de ponta e alporquia, com diferentes concentrações de AIB. Lavras, UFLA, 2010.

Ciência Rural, v.42, n.3, mar, 2012. 


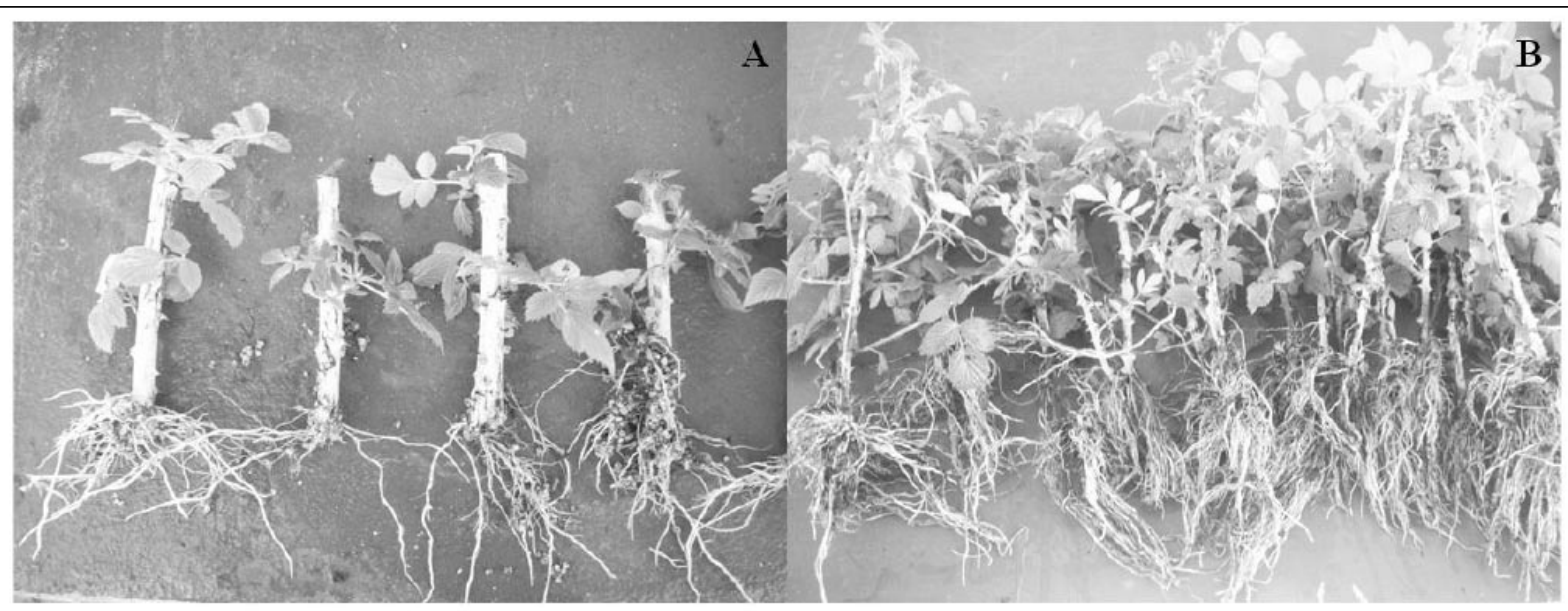

Figura 3 - Sistema radicular formado em estacas de framboeseira negra enraizadas por estaquia (A) e por mergulhia de ponta (B), sem o tratamento com AIB. Lavras, UFLA, 2010.

potencial rizogênico da mergulhia de ponta em comparação com as estacas caulinares.

\section{CONCLUSÃO}

Estacas caulinares possuem maior potencial rizogênico. Não é necessário usar o AIB e armazenar as estacas a frio. A mergulhia de ponta promove maior emissão de raízes.

\section{REFERÊNCIAS}

ANTUNES, L.E.C. Amora-preta: nova opção de cultivo no Brasil. Ciência Rural, v.32, n.1, p.151-158, 2002. Disponível em: $<$ http://www.scielo.br/scielo.php?script=sci_arttext\&pid=S010384782002000100026\&lng=pt\&nrm=iso\&tlng=pt $>$. Acesso em: 11 mar. 2011. doi: 10.1590/S0103-84782002000100026.

ANTUNES, L.E.C. et al. Propagação de cultivares de amoreirapreta (Rubus spp.) através de estacas lenhosas. Revista Brasileira de Fruticultura, v. 22, n.2, p.195-199, 2000.

DANELUZ, S. et al. Propagação da figueira 'Roxo-de-Valinhos' por alporquia. Revista Brasileira de Fruticultura, v.31, n.1, p.285-290, 2009. Disponível em: <http://www.scielo.br/ scielo.php? script =sci_arttext \& pid=S $0100-$ $29452009000100041 \& \operatorname{lng}=p t \& n r m=i s o \& t \operatorname{lng}=p t>$. Acesso em: 11 mar. 2011. doi: 10.1590/S0100-29452009000100041.

JIN, C. et al. Ethnobotanical studies on wild edible fruits in southern yunnan: folk names, nutritional value and uses. Economic Botany, v.53, n.1, p.2-14, 2008.

HAN, H. et al. A review on the molecular mechanism of plants rooting modulated by auxin. African Journal of Biotechnology, v.8, n.3, p.348-353, 2009.
LORENZI, H. et al. Frutas brasileiras e exóticas cultivadas (de consumo in natura). Nova Odessa: Instituto Plantarum, 2006. 640p.

MOYER, R. et al. Antioxidant compounds in diverse Ribes and Rubus germplasm. Acta Horticulturae, n.585, p.501-505, 2002.

PARMAR, C.; KAUSHAL, M.K. Rubus niveus. In: PARMAR, C.; KAUSHAL, M.K. Wild Fruits of the Sub-Himalayan Region. New Delhi: Kalyani Publishers, 1982. p.88-91.

PIO, R. et al. Enraizamento de estacas juvenis do marmeleiro 'Japonês' estratificadas a frio e tratadas com AIB. Ciência e Agrotecnologia, v.31, n.1, p.71-74, 2007a. Disponível em: $<$ http://www.scielo.br/scielo.php?script=sci_arttext\&pid=S1413$70542007000100011 \& \operatorname{lng}=\mathrm{pt} \& \mathrm{nrm}=\mathrm{iso} \& \mathrm{tlng}=\mathrm{pt}>$. Acesso em: 11 mar. 2011. doi: 10.1590/S1413-70542007000100011.

PIO, R. et al. Propagação do marmeleiro 'Japonês' por estaquia e alporquia realizadas em diferentes épocas. Ciência e Agrotecnologia, v.31, n.2, p.570-574, 2007b. Disponível em: $<$ http://www.scielo.br/scielo.php?script=sci_arttext\&pid=S1413$70542007000200043 \& \operatorname{lng}=$ pt\&nrm=iso\&tlng=pt $>$. Acesso em: 21 novr. 2011. doi: 10.1590/S1413-70542007000200043.

RASEIRA, M.C.B. et al. Aspectos técnicos da cultura da framboeseira. Pelotas: Embrapa Clima Temperado, 2004. 22p. (Embrapa Clima Temperado, Documentos 120).

VILLA, F. et al. Propagação de amoreira-preta utilizando estacas lenhosas. Ciência e Agrotecnologia, v.27, n.4, p.829-834, 2003. Disponível em: <http://www.scielo.br/ scielo.php? script = sci_art text \& pid=S 1413 $70542003000400013 \& \operatorname{lng}=p t \& n r m=i s o \& t \operatorname{lng}=p t>$. Acesso em: 11 mar. 2011. doi: 10.1590/S1413-70542003000400013. 